\title{
La recuperación del estatus profesional del historiador del arte: dificultades y objetivos
}

\author{
Víctor Rabasco García | Universidad Autónoma de Madrid \\ URL de la contribución <www.iaph.es/revistaph/index.php/revistaph/article/view/3482>
}

Actualmente, el historiador del arte como profesional se encuentra ante un problema de identidad. No se sabe muy bien cuáles son sus funciones y competencias porque no están definidas, ni a nivel académico ni a nivel laboral, y esto supone un grave problema para su futuro ya que otras profesiones comienzan a ofrecerse para solventar los vacíos que genera este conflicto.

Para tratar de entender cómo se ha llegado a esta situación, hay que pensar en la concepción que se tiene sobre la disciplina de la historia del arte a nivel social. Esta titulación es vista (al igual que ocurre con otras ciencias humanas) como algo "bonito" para estudiar, y resulta atractivo por su aparente facilidad para el aprendizaje. Sin embargo, ha de concebirse como cualquier otra disciplina del saber, pues un buen profesional de la historia del arte debe estar formado en múltiples especialidades según su ámbito de estudio, por lo que la formación histórico-artística es mucho más completa y compleja de lo que puede parecer.

Quizá sea una de las profesiones que más precisan de la interdisciplinariedad como pilar fundamental $y$, ante esto, no son pocas las alusiones al refrán "conocedor de todo, experto en nada", una de las críticas más habituales que recibimos. Realmente este es un punto débil de la titulación, visto desde el aprendizaje, pues un campo de estudio tan extenso hace que terminemos la titulación con conocimientos poco profundos y demasiado amplios.

Esto, sin lugar a dudas, es un factor importante que sitúa en desventaja al historiador del arte frente a otros profesionales. Por tanto nos encontramos ante un primer problema que parte desde el enfoque social inicial que se le da a nuestra disciplina. Se trata de algo palpable desde el propio proceso de enseñanza en primaria y secundaria, donde, en el mejor de los casos, la historia del arte queda relegada a las últimas páginas de los libros de historia.

Otro obstáculo al que nos enfrentamos es la incompleta metodología docente. Tradicionalmente la historia del arte fue una disciplina teórica; tal es así que la primera salida laboral que se viene a la cabeza cuando presentamos nuestra profesión es la docencia. Para cambiar esta mentalidad hay que pensar nuevamente en el proceso de formación, la base educativa sobre la que nos constituimos como profesionales. El mercado laboral demanda (en mayor o menor medida) nuevos trabajadores que estén capacitados con las mejores aptitudes para cubrir las necesidades de una sociedad que evoluciona y, como tal, el historiador del arte debe adecuarse y reformarse. Para ello resulta imprescindible la realización de prácticas durante el periodo de formación; las cuales deberían ser, si no obligatorias, muy recomendables. Sin embargo, la oferta de estas prácticas universitarias no es tan numerosa como para dar cabida a todos los alumnos demandantes. Tal es así que algunos estudiantes tienen que buscarlas por cuenta propia e, incluso, superar varios procesos de selección para ser aceptados en un puesto sin remunerar en la mayoría de ocasiones. Prácticas en instituciones culturales, de investigación, en museos y galerías, yacimientos, etc., pero, definitivamente, una manera de poder desarrollar todo aquello que se ha aprehendido y, a su vez, una manera más de seguir aprendiendo.

Vistos algunos de los problemas sobre los que partimos de base, la mayor preocupación a nivel colectivo es definir bien las capacidades y el marco legal en el que se desenvuelve la profesión del historiador del arte. Arquitectos, médicos, arqueólogos, enfermeros o abogados son algunas de las ocupaciones que han decidido 
a debate Historiadores del arte ¿para qué? Una titulación en busca de una profesión | coordina José Castillo Ruiz

agruparse en colegios para delimitar sus competencias profesionales y, a la vez, tener una capacidad de representación. Al igual que ellos, los historiadores del arte deberíamos buscar un órgano similar con el mismo fin, y así evitar vernos afectados por problemáticas y diferencias con otros profesionales, como ocurre en el caso de los guías turísticos.

En este sentido pondré un ejemplo práctico: si un guía ha estudiado una titulación que le ha enseñado las claves sobre cómo gestionar y desarrollar visitas guiadas y tiene los conocimientos histórico-artísticos necesarios para llevar a cabo una buena explicación, ¿por qué no va a poder desarrollar su trabajo? Ahora bien, un historiador del arte que ha estudiado en profundidad el mismo monumento, e incluso puede haberle dedicado parte de su investigación, ¿por qué ha de tener menor competencia para desarrollar la misma actividad? Nuestro ámbito profesional no está bien definido legalmente, y este es uno de los problemas más urgentes por resolver. El patrimonio histórico-artístico, hoy en día concebido como parte del patrimonio cultural, debería ser competencia de los historiadores del arte y, por tanto, que fueran ellos los encargados de gestionarlo en todos los aspectos. Así pues, debemos reivindicar y dejar claras cuáles son nuestras funciones y objetivos como profesionales dentro del mercado laboral.

En definitiva, se antoja necesario realizar una revisión en profundidad sobre la consideración del historiador del arte para, de esta forma, dotarlo social y laboralmente de la "profesionalización" que parece haber perdido. De ello debería encargarse ese colegio aún inexistente, esa agrupación que nos permitiera ejercer nuestra profesión con total autonomía, adecuándose las especialidades a las diferentes necesidades del patrimonio históricoartístico. Un colegio de historiadores del arte que, tarde o temprano, tendrá que fraguarse ante una importante problemática laboral. Una necesidad para la historia del arte como profesión.

Este artículo, hasta la publicación de revista ph 85 (abril 2014), había suscitado dos comentarios por parte de los lectores del preprint de Perspectivas. La sección permanece abierta a la participación, incluso después de la publicación del número que origina el debate. Sólo los lectores registrados pueden comentar y leer los comentarios de otros. 